NASA Technical Memorandum $827 \leqslant 3$

\title{
The Use of Optimization Techniques to Design Controlled Diffusion Compressor Blading
}

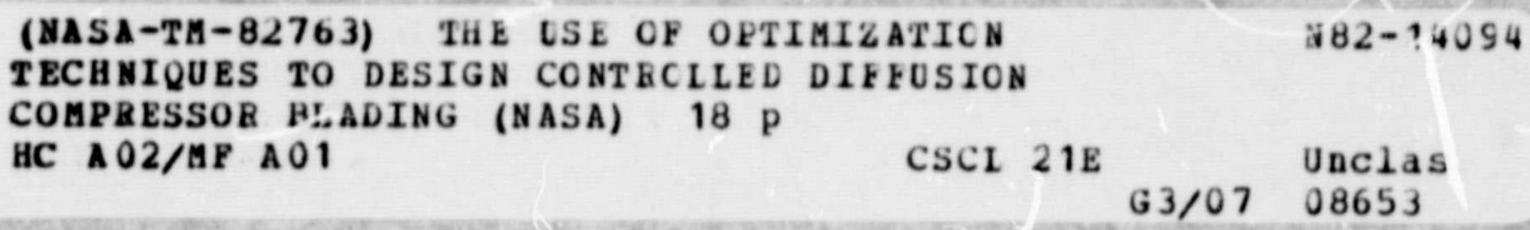

Nelson L. Sanger Lewis Research Center Cleveland, Ohio
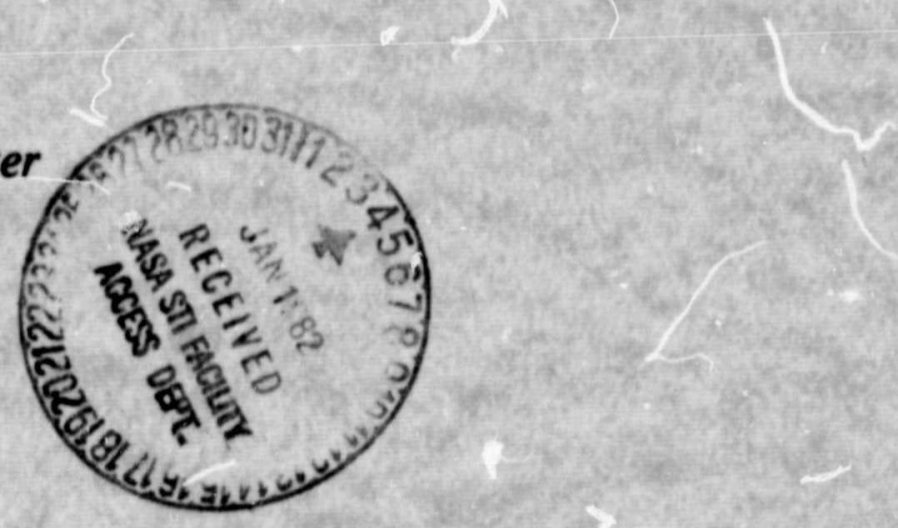

Prepared for the

Twenty-seventh Annual International Gas Turbine Conference sponsored by the American Society of Mechanical Engineers London, England, April 18-22, 1982 
NASA Technical Memorandum 827<smiles>[Tl]</smiles>

The Use of Optimization Techniques to Design Controlled Diffusion Compressor Blading

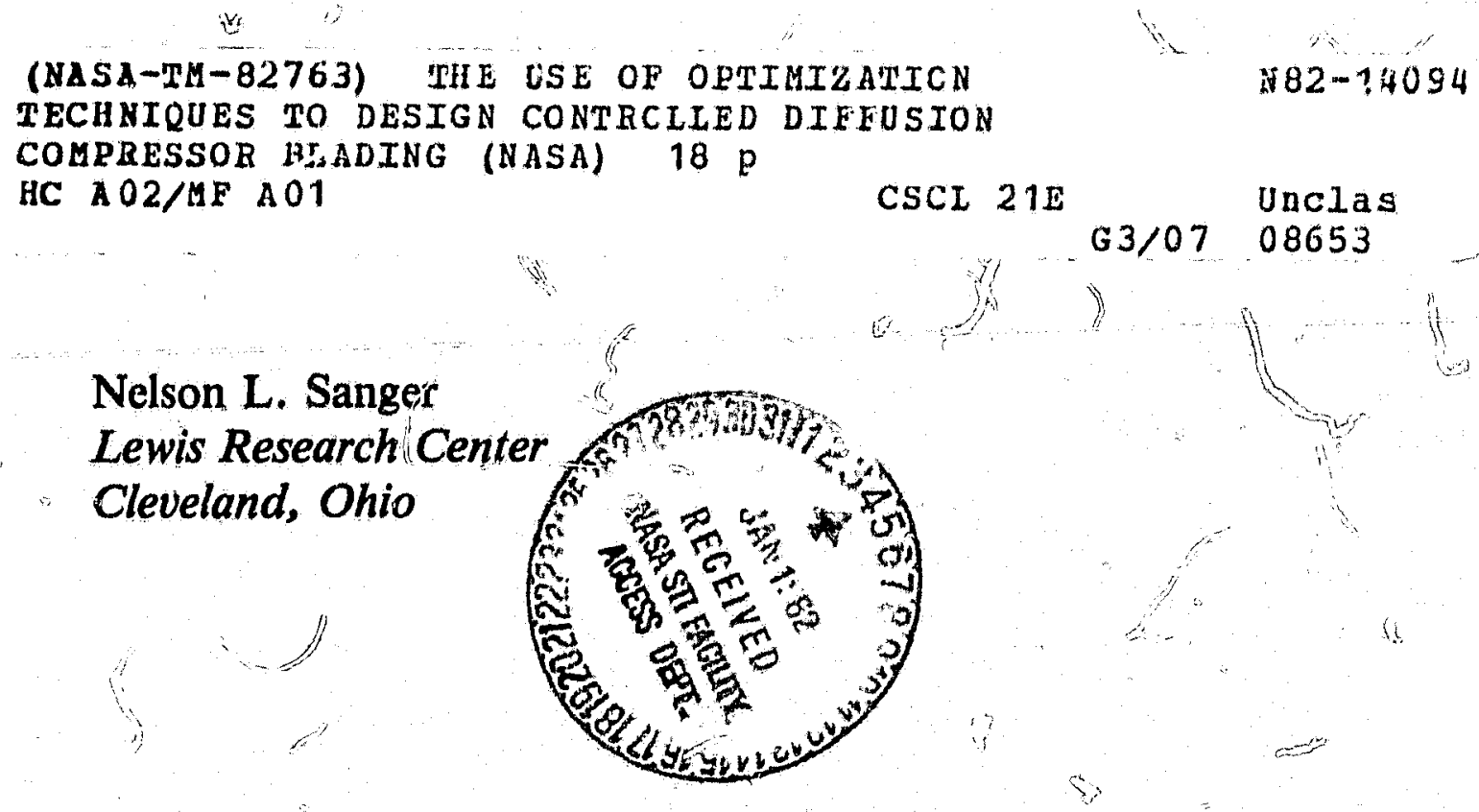

Prepared for the

Twenty-seventh Annual International Gas Turbine Conference sponsored by the American Society of Mechanical Engineers London, England, April 18-22, 1982 
THE USE OF OPTIMIZATION TECHNIQUES TO DESIGN CONTROLLED

DIFFUSION COMPRESSOR BLADING

by Nelson L. Sanger*

National Aeronautics and Space Administration

Lewi: Research Center

Cieveland, Ohio 44135

\section{ABSTRACT}

A method is presented for automating compressor blade design using numerical optimization, and is applied to the design of a controlled diffusion stator blade row. A general purpose optimization procedure is employed, which is based on conjugate directions for locally unconstrained problems and on feasible diractions for locally constrained problems. Coupled to the optimizer is an analysis package consisting of three analysis programs which calculate blade geometry, inviscid flow, and blade surface boundary layers.

The optimization concepts are briefly discussed. Selection of design objective and constraints is described. The procedure for autonating the design of a two-dimensional blade section is discussed, and design results are presented.

*Member ASME. 
THE USE OF OPTIMIZATIÓN TECHNIQUES TO DESIGN CONTROLLED

DIFFUSION COMPRESSOR BLADING

\author{
by Nelson L. Sanger* \\ National Aeronautics and Space Administration \\ Lewi: Research Center \\ C'ieveland, onio 44135
}

\title{
ABSTRACT
}

A method is presented for autonating compressor blade design using numerical optimization, and is applied to the design of a controlled diffusion stator blade row. A generäl purpose optimization procedure is ent ployed, which is based on conjugate directions for locally unconstrained problems and on feasible directions for locally constrained problems. coupled to the optimizer is an analys is package consisting of three analysis programs which calculate blade geometry, inviscid flow, and bilade surface boundary layers.

The optimization concepts are briefly discussed. Selection of design objective and constraints is described. The procedure for automating the design of a two-dimensional blade section is discussed, and design results are presented.

*Member ASME. 
THE USE OF OPTIMIZATION TECHNIQUES TO DESIGN CONTROLLED

DIFFUSION COMPRESSOR BLADING

by Nelson L. Sanger*

Nitional Aeronautics and Space Adminictration

Lewis Research Center

cleveland, Ohio 44135

NOMENCLATURE

$A C 1, B C 1, C C l, O C 1$, $\begin{array}{ll}\text { \& } & A C 2, B C 2, C C 2, D C 2 \\ \text { o } & \text { AT1, BT1,CT1, DT1 } \\ \text { i } & \text { AT2, BT2, CT2, DT2 }\end{array}$

C

$F(\bar{X})$

$G_{j}(\bar{X})$

$\mathrm{H}_{j}$

$H_{i, c r i t}$

L.E.

KCS

KICR

KOCR

KTC

5

s1

52 polynomial coefficients for blade angle distribution expression polynomial coefficients for blade thickness distribution expression chord

objective function

constraint functions

incompressible form factor

critical value of incompressible form factor at which turbulent boundary layer separates.

$\mathrm{H}_{j}$ crit $=2.0$ in this study

leading edge of blade

angle with respect to meridional direction of blade mean line midway between transition location and trailing edge

angle with respect to meridional direction of blade mean line at leading edge

angle with respect to meridional direction of blade mean line at trailing edge

angle with respect to meridional direction of blade mean line at transition location

sezirch direction

distance from transition location along mean line, front segment distance from transition location along mean line, rear segment $s_{m l}$

smle

$S_{\mathrm{m} 2}$

$s_{m 2 e}$

$T$

$t_{1}, t_{2}$

TMX

T.E.

$\mathrm{U}$

$\mathrm{V}$

XCHORD

$2 M$

$\boldsymbol{\alpha}^{\star}$

K

Subscripts:

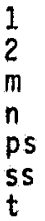

distance from maximum thichess location along mean line, front segmient

distance from maximum thickness location to blade leading edge along mean line

distance from maximum thickness location along mean line, rear segment

distance from maximum thickness location to blade trailing edge a long mean line

distance from leading edge to intersection of two polynomial segments descritsing mean ine/ chord

thickness of blade, front and roar segments respectively

maximum thickness/chord

trailing edge

stream function

surface velocity

vector of design variables

meridional projection of blade chord

distance from leading edge to maximum thickness location/chord move parameter

blade angle

front segment

rear segment

number of constraints

number of design variables

pressure surface

suction surface

transition 


\section{INTRODUCTION}

Throughout the history of compressor technology, blade shapes have been specified by geometric families or elasses. For the most part, these fantilies have been dertved rrom early wing shapes and improved thy empiricism, or have heen directly specified from simple geonetric shapes such as circular arcs and parabolas.

During the past decade, computational methods for the calculation of flow through compressor blade rows have advanced substantially, as have computer speeds. With these advances has conle the capability to rapidly desion and analyzi flow over arbitrary blade shapes. Inded, at the present time, thesil aralysis methods an being synthesized into conputeraided design systidils. In most cases these systenls are "manuaj" F.e., non-automated, Because of the great flexiblity in choice of blade shape, the design process can become quite cumbersome and repetitive unless automated in some fashion. One of the most attractive methods for antomating the design process is numerical notimization. Much progress has been made recently in bringing the technique to bear on engineering problems, particularly in the field of Aeronautics (1). Of the many numierical optimization algor ithms in existence, the one used in kcf. 1 and described in Ref. ? with its control program (3) is sufficientiy general and user-orfented to be of particular interest. It is used in the work reported herein, and is coupled to analysis programs which calculate blade shape, the inviscid flow field, and the boundary layer for a tho-dimenstonal blade section.

With the advent of arbitrary blade shapes, the concept of controlling velocity diffusion (and consequently boundary layer growth) on the suction surface has recefved increasing attention. In the transonic flow regime, such blading has generally been referred to as "supercritical blading" since the local supersonic flow is contralled as well as the boundary layer growth. In the subsonic regime the blading is of ten simply referred to as "controlled diffusion". Methods of analysis have generally been inverse, in which a velocity distribution of a general Stratford type (4) is prescribed at the outset, and a blade shape derived from it (5 and 6).

The problem addressec in the procont work is the redesign of a highmsubsonic stator blade row utilizing a controlled diffusion blade shape. The analytical methods are direct rather than inverse. $A$ blade shape is initially prescribed and aerodynamic performance calculated. Perturbations on the blade shape are effected and aerodynamic pe:-formance recalculated until specified conditions are met. The resulting velocity distributions over the suction surface of the blade are also of the general

stratford type, but in this case are controlled by constraints imposed on the geometric and aerodynamic parameters.

The subject stator row uses the same flow path and velocity triangles as the first stage stator of the NASA TWO-Stage Fan (7). The original design was highly successful, showing a first stage peak adian batic efficiency of 87.0 percent, and a remarkably low radial distribition of loss across the stator. Consequently, significant improvement in performance with controlied diffusion blading cannot be expected, nor is that the purpose of the present work. The arincipal objective of the work presented herein is to develop and demonstrate the feasibility of an automated design procedure based on numerical optimization. Experimental evaluation of the resulting design is planned for both a single-stage envircment and a two-dimensional cascade (midspan biade section).

\section{ANALYSIS METHODS}

\section{Blade Section Geometry}

The blade section geometry is generated by a polynomlal element program. This program has been extracted from the NASA Design Prograln which is a streaml the curvature design procedure (8). Blade section nomenclature is presented in Fig. 1. The meanitine of the blade is described by two polynomfal segments, each of which can be specified by up to a quartic polynomial. The polynomial is a fit of local mean-line blade angle against mean-line distanice. The fraction of chord from the leading edge at winich the two poiynomial segments join is referred to as the transition location. T. The polynonials may be fitted beginning from the transition location and fitting toward the leading edge and tratling edge respectively, or they may be fitted beginning at the leading and trailing edges and fitting toward the transition location. In this report, fitting from transition location toward leading and trailing edges for each segment is the mode of operation. Note that $s_{1}$ and $s_{2}$ are both positive in this minde.

The expression for blade angle distribution is given by Eq. (1): front segment:

$$
k_{1}=k_{t}+A C 1 \times s_{1}+B C 1 \times s_{1}^{2}+C C 1 \times s_{1}^{3}+D C 1 \times s_{1}^{4}
$$

Rear segment:

$$
k_{2}=k_{t}+A C 2 \times s_{2}+B C 2 \times s_{2}^{2}+C C 2 \times s_{2}^{3}+D C 2 \times s_{2}^{4}
$$

A typical distribution of blade angle is shown in Fig. $2(a)$. The blade angle at the transition location is designated as KTC. When fitting from the transition location, the fit is effected from KTC to the blade angle at inlet, KICR (front segment), and from KTC to the blade angle at outlet, KOCR (rear segment). Noted on the figure is a parameter caiculated internally by the program, kas, which is the blade angle midway between the transition location and the trailing edge. This parameter will be of inportance in later discussion.

The distribution of blade thickmass about the mean-line is also specified by two polynomials, both of which may be quartics. The thickness is added symmetricaliy on either side of the meanline. The fit is made from the maximum thickness location toward the leading and tralling edges for front and rear segments respect,ively. The leading edge and trafling edge may be specified as circles or ellipses. Circles only were used in this design. The equations for thickness distribution are given as Eq. (2). Instend of being linear, the first term is of a square root form, which enables simulation of 65-series blades, if desired. 
Front sequent:

$$
\begin{aligned}
t_{1}-\frac{T M X}{2} & +A T 1 \times\left(\sqrt{s_{m 1 e}-s_{m 1}}-\sqrt{s_{m l e}}+\frac{s_{m L}}{2 \sqrt{s_{m L t}}}\right) \\
& -B T 1 \times s_{m 1}^{2}-C T 1 \times s_{m 1}^{3}-\text { DTL } \times s_{m 1}^{4} \quad \text { (2A) }
\end{aligned}
$$

Rear seqment:

$$
\begin{aligned}
t_{2}=\frac{T M X}{2} & +A T 2 \times\left(\sqrt{s_{m 2 e}-s_{m 2}}-\sqrt{s_{m 2 e}}+\frac{s_{m 2}}{2 \sqrt{s_{m 2 e}}}\right) \\
& -B T 2 \times s_{m 2}^{2}-C T 2 \times s_{m 2}^{3}-D T 2 \times s_{m 2}^{4}
\end{aligned}
$$

Patential Flow Solution

The potential flow about the blade section in the two-dimensional, blacle-to-blade plane is calculated by the method developed by Katsanis. TSONIC (9). The progran solves the stream function equation by finite difference techniques for the subsonic, compressible flow regine. It is necessary to specify as input the fluid properties, inlet totol temperature and density, weight flow, blade geometry, inlet and outlet flow angles, finte difference mesh, and a meridional distribution of streamitube height and total pressure loss. In the design presented herein, a linear distribution of streamtube height and estimated total loss was utillized.

Because the nature of the equations dictates that the solution be of a boundary value type, the outlet flow angle nust be specified on the downstream boundary. This efrectively sets the kutta condition. Since this condition is related to one of the constratuts chosen for the optimization process, its discussion will be reserved until later.

\section{Boundary Layer Calculations}

Bade surface boundary layers were calculated using the program developed by McNally (10). in addition to the surface velocities, required input includes upstrean flow conditions, fluid properties, and blade surface geometry. Anong the output provided by the program are the conventional boundary layer thicknesses, form factors, wall friction coefficient, and momentum tilickness Reynolds number.

The program uses integral methods to solve the two-dimensional compressible laminar and turbulent boundary layer equations in an arbitrary pressure gradient. Cohen and Reshotko's method (11) is used for the laminar boundary layer, transition is predicted by the schlicting-UirichGranville method (12), and Sasman and Cresci's method (13) is used for the turbulent boundary layer.

A boundary layer which is initially laminar may proceed through normal transition to a turbulent boundary layer, or it may undergo sol: Eorm of laminar separation before becoming turbuient. To provide flexibility for analyzing this behavior, several program options are available to the user. The calculations may proceed from a laminar boundary layer through transition to tur- bulent calculations. However, if lantinar separdtlon is predicted before transtion, the turbulent calculations may be started by specifying a factor by which the last calculated value of moniention thickness is muitiplied (this value is conmonly chosen to be 1.0 to satisfy conservation of momentum). This new momentum thickness and a value for form factor based on the last calculated momentum thickness Reynolds number are used as initial values for the turbulent calculations.

\section{Optimization Program}

The optimization algorithm in Fortran code is known as CONAIN, and is reported in Ref. 2. A general purpose control progran known as COPES is coupled to the algoritim (3).

The general mathenlatical representation of a numerical optimization problem is stated as:

$\begin{array}{lll}\text { Minimize } & O B J=F(X) \\ \text { subject to } & G_{j}(X)<0 . & j=1, m \\ & X_{j}^{l}<X_{i}<X_{j}^{U} & f=1, n\end{array}$

$X$ is a vector consisting of the design variables. $x_{i}$ and $x_{j}^{0}$ are the lower and upper bounds on the desinn variables and are referred to as side constraints. $O B d$ is the objective function. If the designer wishes to maximize a function, OBJ may be defined as the negative of the function. $G_{j}(\bar{X})$ set the constraint functions which the design must satisfy. When $G_{j}(\bar{X})<0$, it is said to be inactive; when $G_{f}(X)>0$, it is violated. When it is within a tolerance band about zoro, it is active. $F(\bar{X})$ and $G_{j}(\bar{X})$ may be inplicit or explicit functions of the design vartables $X$, but must be continuous. (Note: this should be carefully considered when formulating these functions when they are calculated from finite difference solutions or at discrete stations.) An initial design vector, $\bar{R}$, is specified by the user. It may be feas lble ol infeasible, i.e., if it satisfies the incqualities of $\mathrm{Eq} .(3)$, it is feasible. If a feastble initial design can be found, it is usually more efficlent to begin with it, at least for the types of problems discussed herein. An iteration process is then begun which follows the recursive relationship:

$$
x^{q+1}=x^{q}+a * s^{q}
$$

$q$ is the iteration number; the vector $S$ is the search direction in the n-dimensional space; and the scalar $a^{*}$ (move paraneter) defines the distance of travel in direction $S$, and is found by interpolation.

The search direction $\bar{S}$ is initially obtained by moving in the direction of steepest descent (negative gradient of the objective function) without violating constraints. The procedure is then repeated using a conjugate direction algorithin in determining a new search direction. Whenever a constraint is encountered, a new search direction is found using Zoutendijk's Methoo of Feasible birections. An optimum has been achieved when no search direction can be found which will further reduce the objective function without viclating a constraint. 


\section{OPTIMIZATION OF STATOR BLADE SECTION}

Formulation of a specific optimization problen involves choice of an objective funciton (the quantity to be optimized), choice of constraints, and clioice of desian variabies. In the present design problem, optimization of a two dimensional stator blade section was performed at the 90 percent span from tip section. This location represented the most difficult design problen as measured by blade loading requirements.

Results of preliminary calculations of an inttial blade shape which meets the specified velocity triangles at the 90 percent span location are shown in Figs. 2 to 4 . Figure 2 shows the of tribution of blade angle and blade thickness along the mean-line, and the corresponding blade shape. Floure 3 is the surface velocity distribution corresponding to the blade shown in Fig. 2. And Fig. A represents the incompressible form factor distribution along the suction surface obtained from the boundary layer calculations.

The initial blade design was essentially an arbitrary choice. The blade angle distribution and thickness distribution plots were determined by running the blade geonetry program in a graphics mode. In this mode, the distributions can be generated by curvefitting through points which are input by the user. The process is therefore intuitive, and guided by experfence. The only restriction to the process is the desirability, with regard to optinization theory, that the design be feasible. Note that for the initial desfign selected, the turbulent boundary layer separates at 64 percent of chord.

A properly designed controlled diffusion blade should experience no suction surface boundary iayer separation. This criterion is incorporated the objective function. The following penalty fuction type of objective function proved to be the ros: successful.

$$
\text { OBJ = FORMAX - XSEPQX }
$$

FORMAX is the maximum incompressible form factor $\left(\mathrm{H}_{i}\right)$ occuring ver the rear portion of the blade, and XSEPOX is the separation location of the turbulent boundary layer expressed as a proportion of chord length.

OBJ was minimized. Reducing FORMAX acts to increase the separation location, XSEPOX. Simultaneously reducing FORMAX and increasing XSEPOX acts to reduce $O B J$.

Design Variables

Nine design variables have been selected, all of which describe the geometry of the blade. These variables are:

$T$, transition location of two mean-line polynomials;

ZM, maxinum thickness location;

KOCR, the exit blade mean-line angle (deg.);

$A C 1, B C 1$, first two coefficients of front segm ment mean-line polynomial;

$A C 2, B C 2, C C 2, D C 2$, all four coefficients of rear segment nean-i ine polynomial.

The velocity triangles are fixed for the blads section, thus fixing the loading or overall velocity diffusion across the blade row. By allowing KOCR to vary, the blade camber angle is allowed to change. The trafling edge or Kutta-type condition is controlled through a constraint desiribed below.
Incidence angle is not allowed to vary. It is fixed at the value used in the original design (7) simply as a designer's preference. If it should become desirable or necessary to allow incidence angle to vary, it can easily be incorporated by including KICR as design variable, and retaining the same velocity triangle information.

Although the maximum thickness location, $2 M$, is allowed to vary, the coefflcients of the blade thickness polynomial are held fixed the values used in the prelininary (initial) blade shape, strictly as a desioner's choica.

Each of the above varlables is allowed to vary within user-selected limits. The upper and lower bounds for each are listed below, and in optimization theory are referred to as side constraints. The side constraint values are chosen as a resuit of experience. Beyond certain values, a realistic blade shape will not result. In addition, certain extreme combinations of variables may cause cunvergence problems in the geometry program, and so are best avoided.

Lower Upper Bound Bound

Transition Location/Chord, T Max Thickness Loc./Chord, ZM Outlet Blade Angle, KOCR

All Coefficients

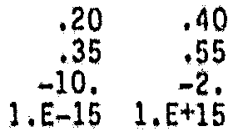

Constraints

Five constraint runctuans are spectified, all being implicit functions of the design variables. Two constraints are variables calculated internally to the geometry program and control the blade angle distribution. By controlling the blade angle distribution, a controlled diffusion type shape to the surface velocity distribution can be insured. The constraints are represented in Fig. $2(\mathrm{a})$, and are KTC and KCS, which were previously described. They were allowed to vary between the following bounds:

\section{Lower Bound Upper Bound}

$\begin{array}{lll}K T C & 32.0 & 46.08 \\ \text { KCS } & -4.0 & 11.05\end{array}$

The remaining constraints are calculated in the inviscid flow program (9) and are described with reference to a surface velocity distribution. Since TSONIC is principally a subsonic calculation procedure, the maximum surface velocity on the suction surface is constrained to the subsinnic fiow reotine, A search procedure locates the maximum suction surface velocity, This is nondimensionalized by the inlet freestream velocity and the ratio is defined as the constraint. The upper bound was set to be equivalent to Mach 1 condition. The lower bound is set equal to an arbitrary, small number.

Because no boundary iayer calculations are made on the pressure surface of the blade, a constraint is applied to control the velocity diffusion on the pressure surface. Preliminary calculations weru made of typical blade shapes, and a pressure surface velocity diffusion ( $V$, max/V, min) of 1.65 was deemed to be a sufficiently safe upper bound. Subsequent to the optimization calculation, the pressure sur-m face bouncary layer of the optinized blade is also calculated to verify that it was truly free from separation. The lower bound of this constraint is set equal to an arbitrary, snall number. 
The final constraint is chosen to set the tralling edge condition, the condition equivalent to a Kut \pm a condition. This is also equivalent to setting deviation angle. In the present work, outle flow angle is fixed, so whatever value is taken on by blade outlet angle, KOCR, sets deviation angle. Experience with sone of the conventional fomilies of blades, supplemented with jetallud analyses, permitted guidelines to be set for estimating deviation for those blade families (14). But such experience is lacking for controlled diffusion blading, which is arbitrary in shape. For conventional blading, setting the deviation angle such that the suction surface and pressure surface velocity distributions clnse inside the trailing edge at perhaps 85 to 90 percent of chord, was one possible means for accounting for the effect of 1 rounded tralling edge and boundary layer sepiration over the rear portion of the suction surface. For controlled diffusion blading, the object is to have no boundary layer separation. If this is accenp1 ished, the deviation angle wou iu be expected to be snall, and there would be justification for allowing the suction surface and pressure surface velocities to close at the trailing edge, rather than closing earliter.

The constraint is defined as a non-dimensional difference between velocities on the suction and pressure surfares at the trailing edge mesh line, and is expressed:

$$
\frac{\left(V_{s s}-V_{p s}\right)_{T . E .}}{15.24}
$$

The denominator, 15.24, was chosen to scale the constraint to about order one. Upper bound was set. at zero and lower bound at $-1,25$. The velocity difference at the trailing edge could vary between an upper bound of zero and a lower bcund of $-19.0 \mathrm{~m} / \mathrm{sec}$, thus permitting some closing inside the trailing edge.

\section{MODIFICATIONS OF ANALYSIS PROGRAMS}

An important requirement of the optimization method is that the objective and constraint functions by continuous functions of the design variables. This necessitated certain modifications of the analys is progranis.

\section{Modification of Inviscid Code}

Experience with the TSONIC code has shown that calculations in the trailing edge region can be quite sensitive for some configurations. Orientation of the blade, trailing edge radius, and grid intersection points can affect surface velocity calculation at or near the trailing edge station, sometimes resulting in spurious behavior. Inaccurate trailing edge velocities will produce incorrect gradients of the tralling edge constraint described above, and possibly give misleading violations of that constraint.

The means used to avoid or reduce this tendency is to incorporate a niass injection model at the trailing edge (15). In this model, tangents are formed at the intersection of the trailing edge circle with the blade surface, and extended to the vertical grid line which forms a tangent with the trailing edge ctrcle (Fig. 5). The "wake" is then extended downstream with an orientation deterinined by the downstream whirl boundary condition. Experi- ence has shown this modeling to reduce the sensttivity of the surface velocity calculations in the trailing edge region.

\section{Modif ications of Boundary Layer Code} There is presently no agreement concerning tho inftial tate of boundary layer on a compressor stator blade in the real flow environment. Some observors have measured laminar boundary layers, while others contend that due to high inlet turbuience and unsteady effects, a laminar boundary layer cannot persist. For the purposes of this stuay, the question is somewhat acadenic. An optinization design process can be developed for efther case. In the present "work the existence of a lamtnar boundary layer is assumed, which poses the nore difficult optimization problem.

The location of laminar separation and turbulen! reattachment is of cruclal importance to the optimization search process. The suction surface velocity distribution provided as input to the boundary layer calculation might ideally appear as represented in Fig. 6(a). In reality it might appear as in Figs. $6(\mathrm{~b})$ and (c), due to the interrelationship of geometric variables such as blade stagger, solidity, camber distrthution, thickness distribution, transition location, and maximum thickness location. Boundary layer calculations are initiated with a laminar boundary layer, which would usually persist to point $A$. Laminar seperation, rather than normal transition, occurs there in all cases because of the steep adyerse pressure gradient. Conservation of momentum is assumed through the laminar eparation region, with the turbulent boundary layer reattached at the next calculating station. Turbulent separation is assumed to occur when the incompressible form lactor reached a critim cal value.

As originally indelled, point $A(F i g, 6)$ is identified as the station at which skin friction hecones negative. Any sensitivity to design variables can cause a discontinuous jump in point: $A$ location. This effect carries through to directly influence turbulent boundary layer separation location and the objective function. To establish a consistent and conservative criterion, the following procedure was coded. Usting Lagrangian internolation, three additional points are placed between each station in the high gradient region of the velocity vs. distance array. A search procedure is begun from the trailing edge region, and locates the maximum velocity at the beginning of the high gradient region, point $B$ in Fig. 6 . Laminar separation and turbulent reathachient is effected at poin' $B$.

In addition to the modifications dis:ussed above, several modifications were required relating to turbulent boundary layer separation. A separation criterion comion to compressor blade analyses which use integral boundary layer methods is the inconpressible form factor. $H_{f}$. Values of 1.8 to 2.6 have been proposed and used in the past (e.g., von Doenhoff and Tetervin, Ref. 16). A value of 2.0 is somewhat conservative and, in the experience of the autlior, has proven to be useful the program was nodified to use 2.0 as the critical incompress 1. ble form factor.

In normal operation, when a form factor at a given station exceeds 2.0, separation is assumed to have occurred at that station. If calculation stations are 5 percent of chord apart, separation location becomes a discontinuous function, changing with distance in 5 percent jumps. To correct this, 
linear interpolation is used between stations to obtain the percent chord location corresponding to $\mathrm{H}_{1}=2.0$.

Because of the relation between blade angle distribution and thickness distribution, the incompressible form factor quite of ten resembles F19. 7. A maximum form factor can be oluserved at C. A more conventional form factor distribution is aiso depicted in $F$ ig. 7, where the maximum value is identiffed as $D$. A search procedure was added to locate the maximum form factor, formax, which is one term in the objective function.

It was observed that allowing turbulent reattachment at momentum thickness equivaient to momentum thickness at laminar separation of ten resulted in initial turbilent momentum thickness Reynolds numbers less than 320 , the minimum value experimentally observed for a turbulent boundary layer (17). Therefore, as final modification, the code was altered to provide a minimum thickness equivalent to a Reynolds number of 320 .

\section{DESIGN RESULTS}

The optimization history is shown in Fig. 8. Most improvement occurred in the first two iterations. At the end of two iterations a blade had been found with no boundary layer separation $(X S E P O X=1,0)$. Reduction of the objective function for subsequent iterations involved reduction of FORMAX nitly, since XSEPOX remained 1.0. All im provement beyond iteration 2 provided more safety margin from the theoretical separation condition. CPU time on an IBM $370 / 3033$ for the ejght iterations was 49.48 minutes. A total of 85 calls on the analysis programs were made.

The initial and final blade shapes, surface velocities, and suction surface boundary layer form factor are presented and compared in Fiss. 9 to 11. The pressure surface boundary layer form factor is presented in Fig. 12.

In the course of optimization, the geometric transition location moved forward from 27.3 percent of chord to 24.1, and the level of KTC (blade angle at transition) shifted downward from 36.7 degrees to 34.8 (Fig. 9). The maximum thickness location moved rearward from 48.2 percent of chord to 53.6. All pclynomial coefficients describing the blade angle distribution were altered, as would be expected, since they were design variables. The polynomial coefficients describing the thickness distribution were not altered, since they were not design variables. However, since the maximum thickness location itself changed, the actual distribution of thickness was aitered, as is evident from $F i g$. 9 (b). If difficulties in achieving a satisfactory design had been cxperienced, the polynomial coeff $j_{-}$ cients for thickness distribution could have been addeo as additional design variables, but at the cost of increased computing time. Outlet blade angle, KOSR, changed little during the process. Large excursions in KOCR were prevented because it is closely related to the trailing edge constraint (Eq. (6)).

The changes effected in the surface velocities by the optimization procedure (Fig. 10) are a bit more dramatic in appearance than are the geometry changes. The peak velocity on the suction surface was reduced, as was the large velocity diffusion over the front portion of the pressure surface. The unconventional waviness of the pressure surface velocity is due to the aft location of the maximum thickness. Fitting the thickness distribution through this maximum thickness location, in combination with the forward transition location, results in a region of reversed curvature on the pressure surface near the maximum thickness location, and is evident on Fig. 9(c). The effect on the flow carries across the channel and appears as a small wave on the suction surface as well. Aside from the dublous aesthetic appearance, no adverse aerodynamic effects can be attributed to this behavior. The calculated boundary layers appear well-behaved. with the maxtmum incompressible form factor on the s:Jction surface being 1.924, and on the pressure surface 1.780 .

In completing the design of the stator, only one other blade section was sptimized, the hub section at the inner endwall. This blade element will be in the wall boundary layer, so that true twodimensional flow is not expected to exist. Resulting transition location and maximum thickness location wire not greatiy different from the values found at the 90 percest span location. Blade angle polynointal coefficients different from those obtained at 0 percent span were obtained. However, for reasons relating to the blade stacking procedure, which will be described below, the polynomia? coefficients obtained at the 90 percent span location were used also at the 100 percent span. The resulting two-dimensional calculations for the blade with these coefficlents indicated no boundary layer separation.

All other blade sections were speciffed based on the optimized design obtained at the 90 percent: span section. Each of these blade sections, which ife on streamilies, fi, thin radially stacked.

Fabrication coordinaces sre interpolated at several planes parallel to the axis of rotation of the comm pressor. In principle, each of the blade sections on the six chosen streamilnes utilized could be designed by optimization. This could and probably would result in six different sets of transition location, mayimum thickness location, and blade angle poijnomial roefficients. The fabrication cocrdinates are generated by a design point streamline curvature code. As input to this code, a radial curvefit of each of the polynomial coefficients must be provided. Transition location and maximum thickness location for each blade section are input directly. The blade coordinates on each streamline section are then generated. Finally, coordinates at the horizontal fabrication planes are obtained by interpolation, based on a cubic fit of the blade coordinates at the four stri-amlines most closely straddling the desired fabrication plane. Because of the curvefitting at various stages of this process, prudence suzgests avoiding the possibility of iarge radilu variations in the design parameters. Therefore, a constant radial distribution of each parameter was sought, with one exception. Maximum thickness location was arbitrarily moved forward to 47 percent of chord for all sections between the tip and 70 percent of span from tip. Although it was not necessary to do this, the effect was to relieve the reversed curvature condition on the pressire surface. The transition location and all polynomial coefficients were maintained at the same values obtained for the optimized 90 percent span section. At the 100 percent span section, transition and maximum thickness locations found from optimization at that section were used $(0.26$ and 0.52 respectively), and blade angle polynomial coefficients equivalent to those at 90 percent span were used. Thus, neither the polynomial coefficients for blade angle nor maximum thickness 
varied radially. Transition location was constant from tip to 90 persent span, and differed only slightly at 100 percent span. Maximum thickness location was constant from the $t$ ip to 70 percen". span at 0.47 , moved rearward to 0.53 at 90 percenti span, and slightly forward to 0.52 at 100 percent span. The exit blade angle, KOCR, varied only slight ly from tip to hub in a range from -3.7 to -4.0 . Since design exit flow angle is zero degrees for all sections, the negative value of KOCR represents deviation angle. If, indeed, the boundary Tayf,r does not separate from the blade as theoretically predicted, the deviation angles of about 4 degrees may be more realistic than they appear to be. The w! tue geometry and surface velocity distributions for the blade sections at midspan and 10 percent span from tip are sliown in Figs. 13 and 14.

\section{SUMMAFYY AND CONCLUDING REMARIIS}

A method has been presented for automated compressor blade design using numierical optimization techniques. The method was applied to the design of a controi: H-diffusion stator blade row. Tiree analysis prugrams were coupled to the numerical optimization program: a blade geometry generation program which uses polynomial representation for blade angle and thickness distributions, a compressible, inviscid flov program, and an integral boundary layer program. Seven of the nine design variables were related to blade angle distribution, another located the maximum thickness of the blade, and the last controlled camber and deviation angles. Two constraint functions operated in the geometry program to produce shapes with controlled diffusion velocity oistributions. Constraint functions applied in the flow andiysis prograys limfied suction surface velocities to the subsonic regime, linited the velocity diffusion on the pressure surface, and set the tratling edge condition for inviscid calculations. The objective function, which was minimized, was of a penalty function form, and effectlvely produced a blade whose suction surface turbulent boundar's layer did not separate. The optimization procedure for the subject blade section required eight major iterations involving $85 \mathrm{calls}$ on the geometry/aerodynamic anaiysis programs. Total CPU time on an IBM $370 / 3033$ computer was 49.02 minutes.

When using the numerical optinization procedure, it was essential that the gradients of the constraint and objective functions be smooth and accurate. Therefore, some modifications of the analysis programs were necessary to ensure that these functions were continuous.

The design problem, as formulated here, produced a blade shape which satisfied the design criteria, while holding the polynomial coefficients describing thickness distribution, the value of maximum thickness, and the incidence angle constant. The methed thus still offers great flexibility for adaptation to more demanding design requirements.

\section{REFERENCES}

1 Vanderplaats, G. N., "The Computer for Design and Optimization," Computing and Applied Mechanics, AMD-Vol. 18, American Society of Mechanical Englneers, New York, 1976, pp, 25-48.

2 Vanderplaats, G. N., "CONMIN a Fortran Program for Constrained Function Minimization, User's Manual," NASA TM X-62282, 1973.

3 Vanderplaats, G. N." "COPES a Fortran Control Program for Engineering Synthesis," Naval Postyiduate School, 1980.

4 Stratford, B. S., "The Prediction of Saparation of the Turbulent Boundary Layer," Journal of Fluid Mechanics, Vol. 5, Pt. 1, Jan. 1959, pp. 1-16.

5 Papafliou, K. O., "Boundary Layer Optimization for the Design of High Turning Axial How Compressor Blades," ASME Paper No, 70-GT-88, 1970.

6 Stephens, H. E., "Application of Supercritical Airfall Techrology to Compressor Cascades: Comparison of Theoretical and Experimental Results." BIAA Paper No. 78-1138, July 1978.

7 Urasek, D. C., Gorrell, W. T., and Cunnan, W. S., "Performance of Two-Stage Fan Having LowAspect-Ratio, First-Stage Rotor Blading, "NASA TP-1493. Aug. 1979.

8 Crouse, J. E., and Gorrell, W. T., "Computer Program for Aerodynamic and Blading Design for Multistage Axial-Flow Compressors," Proposed NASA TP*

9 Katsanis, T., "Fortran Program for Calculating Transonic Velocities on Blade-To-Blade Stream Surface of a Turbomachine," NASA TN D-5427, 1969.

10 Nickaliy. W. D. "Fortran Program for Calculating Compress ible Laminar and Turbulent Boundary Layers in Arbitrary Pressure Gradients," NASA TN D-5681, 1970.

11 Cohen, C. B, and Reshotko, E., "The Conk pressible Laminar Boundary Layer with Heat Transfer and Arbitrary Pressure Gradient," NACA TR-1294. 1956.

12 Schlicting, H., "Origin of Turbulence II," Boundary-Layer Theory, 7th Ed., McGraw-Hill, New York, 1979, pp. 489-554.

13 Sasman, P. K. and Cresci, R. J. "Compressible Turbulent Boundary Layer with Pressure Gradient and Heat Transfer," AIAA Journal, Vol. A, No. 1, Jan. 1966, pp. 19-25.

14 Sanger, N. L., "Two-Dimensional Analytical and Experimental Performance Comparison for a Compressor Stator Section with D-Factor of 0.47 ," NASA TN $0-7425$, Oct. 1973.

15 Katsanis. T., Unpublished Addendum to Reference 9 .

16 Von Doenhoff, A. E. and Tetervin, N., "Determination of General Relations for the Behavior of Turbulent Boundary Layers," NACA Wartime Report L-382, 1943.

17 Preston, J. H. "The Minimum Reynolds Number for a Turbulent Boundary Layer and the Selection of a Transition Device," Journal of Fluid Mechanics, Vol. 3, Pt. 4, Jan. 1958, pp. 373-384. 

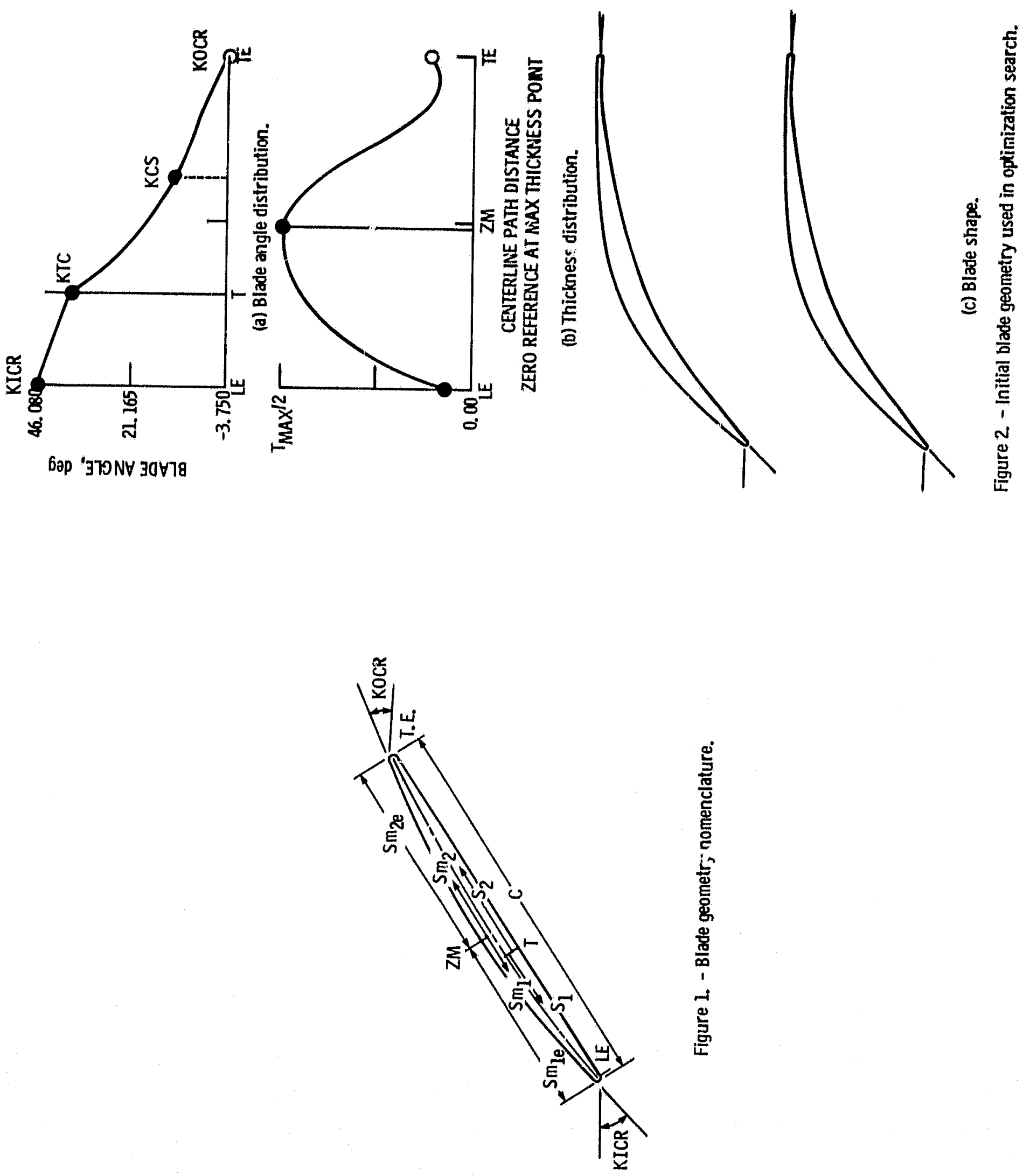


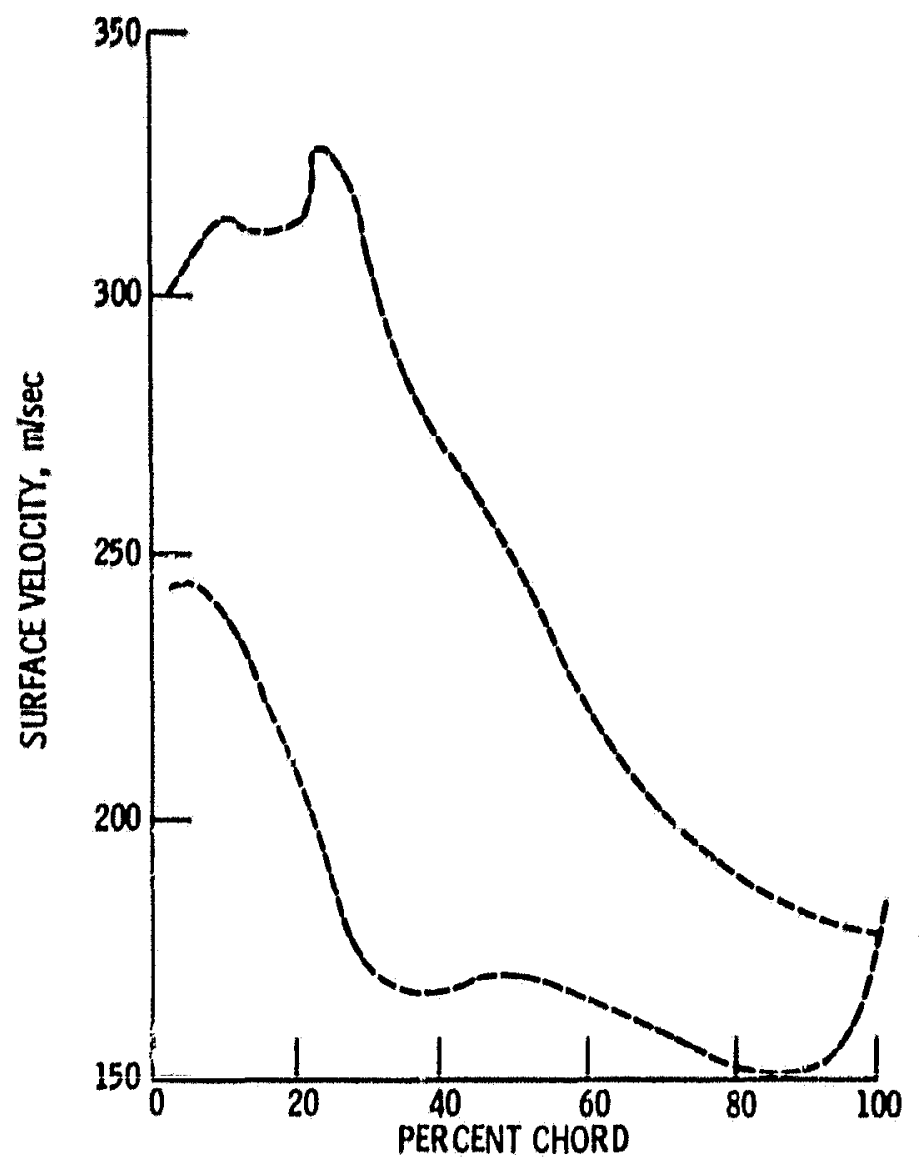

Figure 3. - Initial surface velocily distribution.

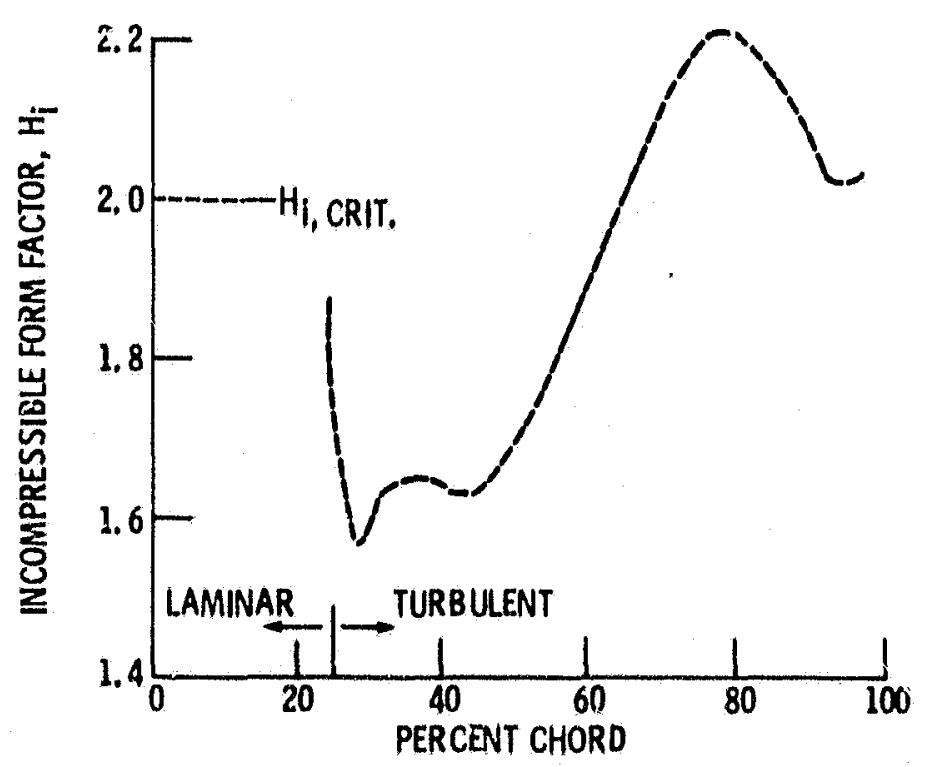

Flgure 4. - Initial design-suction surface turbulent boundary layer form factor distribtion. 


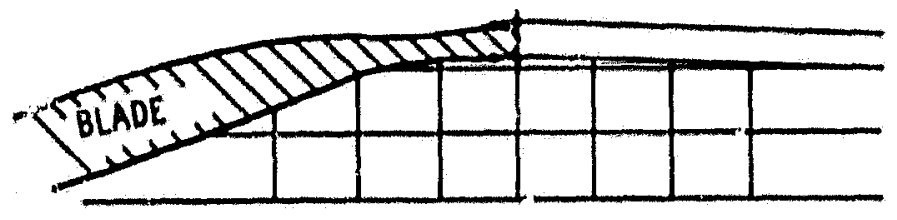

(a) Construction of effective wake.

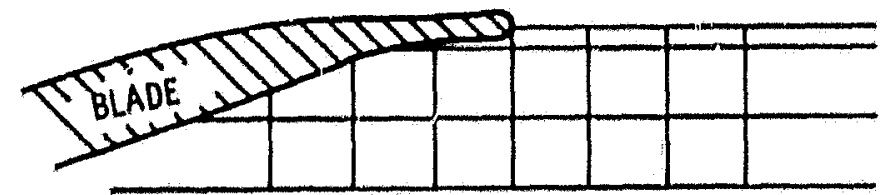

(b) Original trailing edge model (ret. 9),

Figure 5. - Mass flow injectlon model: TSONIC program.

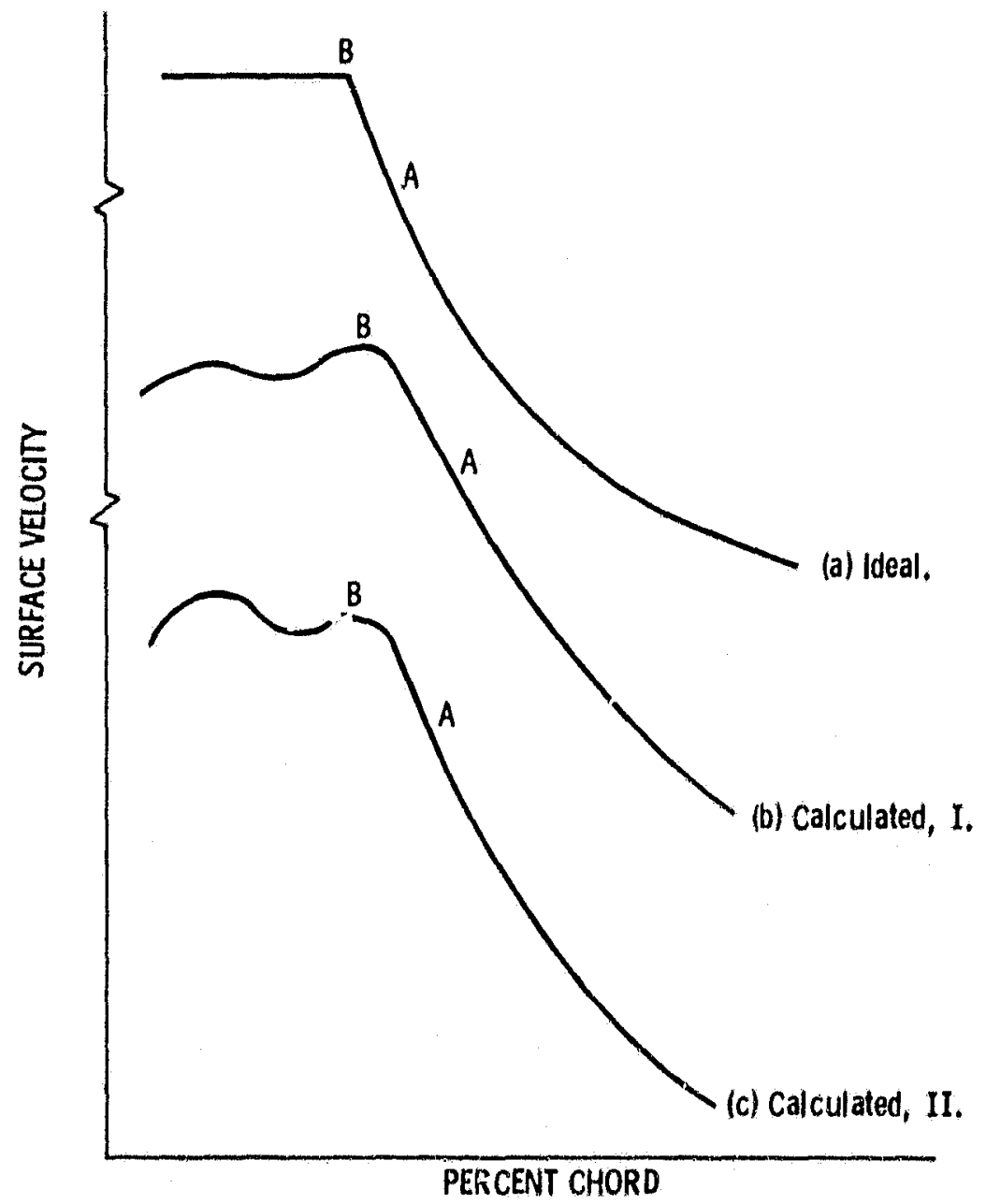

Flgure 6. - Representation of ideal and calculated suction surface velocities. 


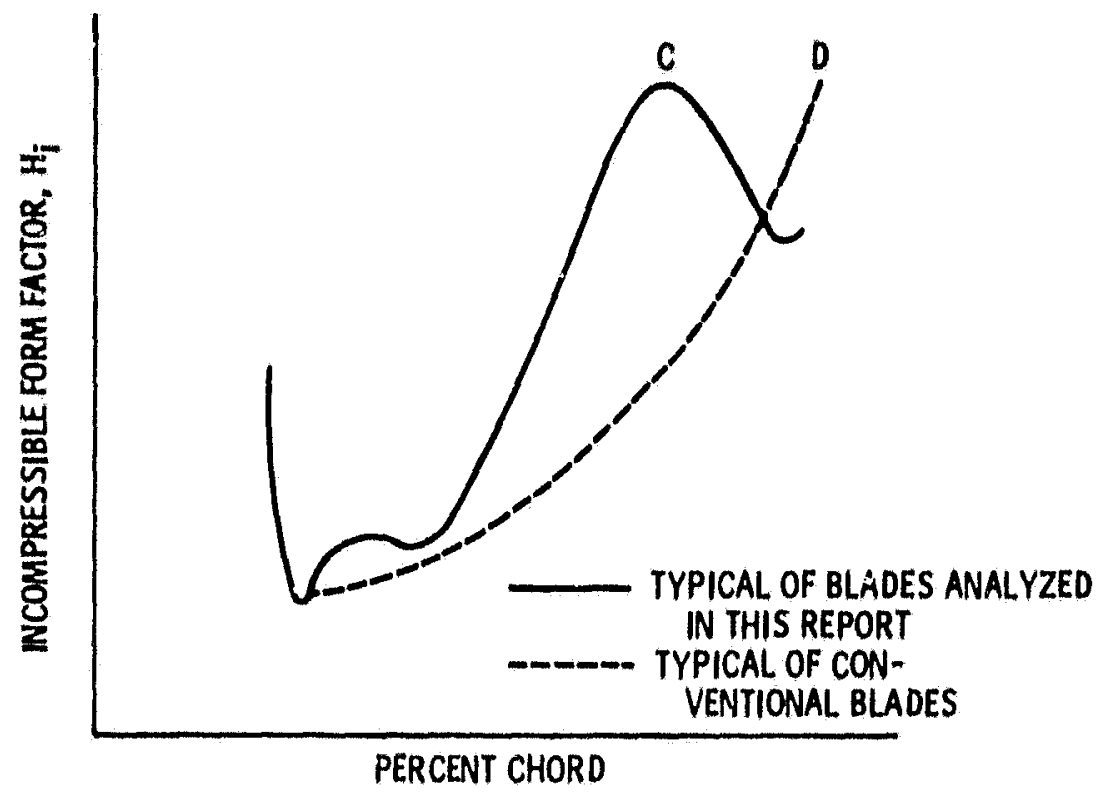

Figure 7. - Turbulent insompressible form factors for different classes of blacies.

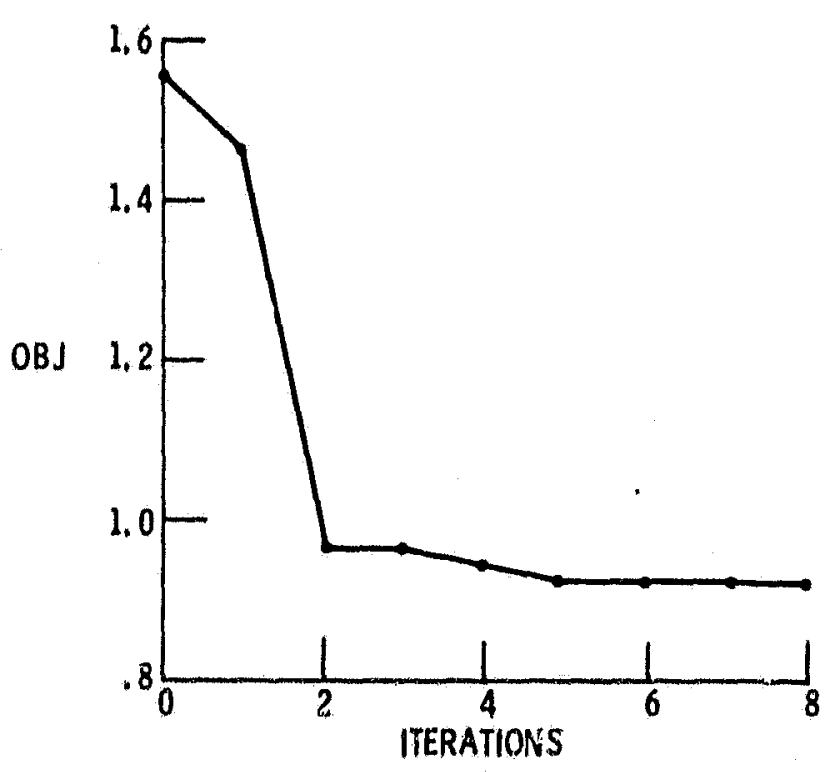

Figure 8. - Optimization history. 


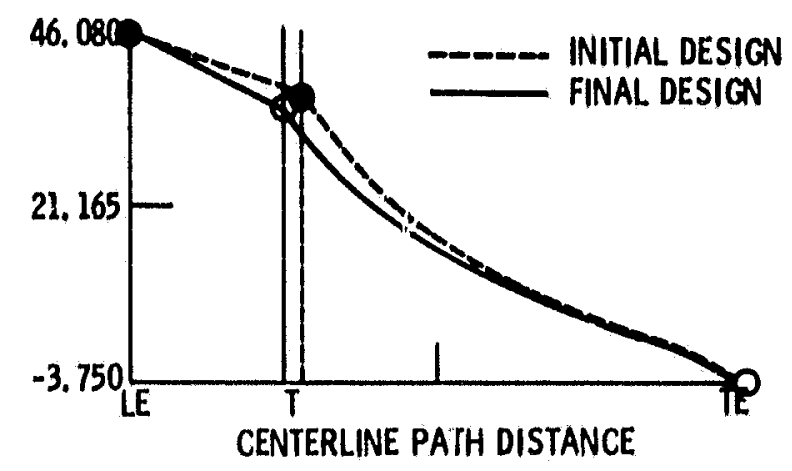

(a) Blade angle dilstribution.

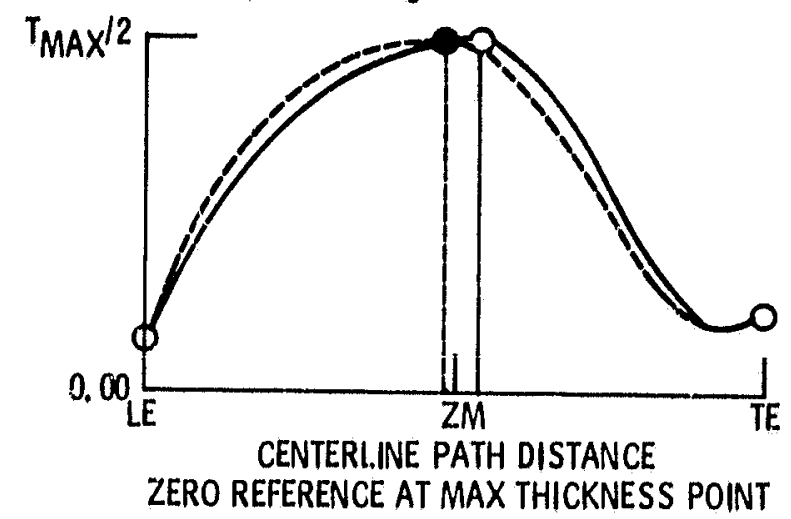

(b) Thickness distribution.
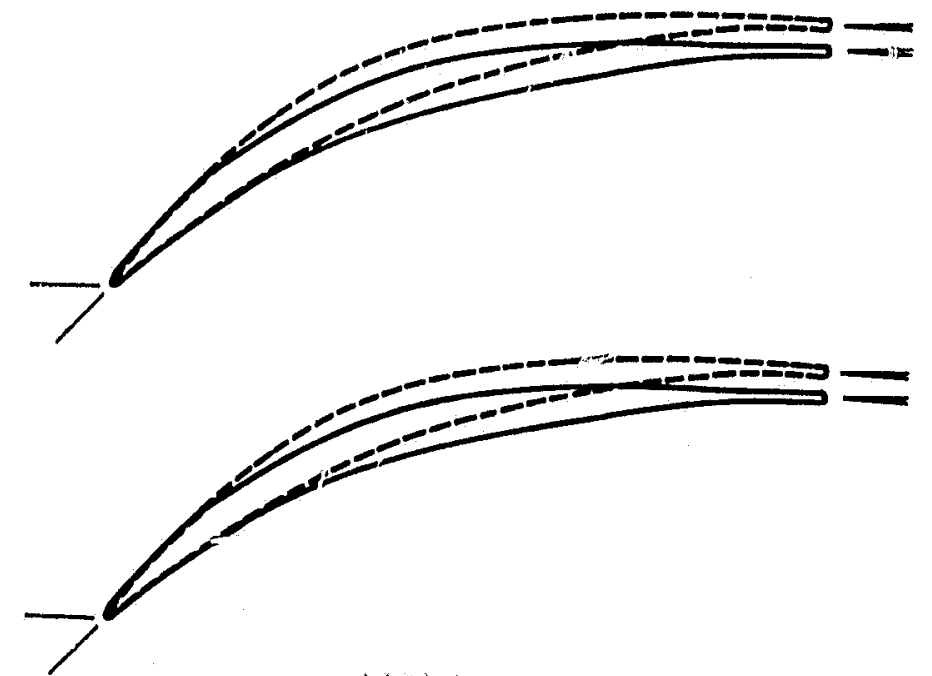

(c) Blade shape.

Figure 9. - Comparisons of initial and final blade designs. 

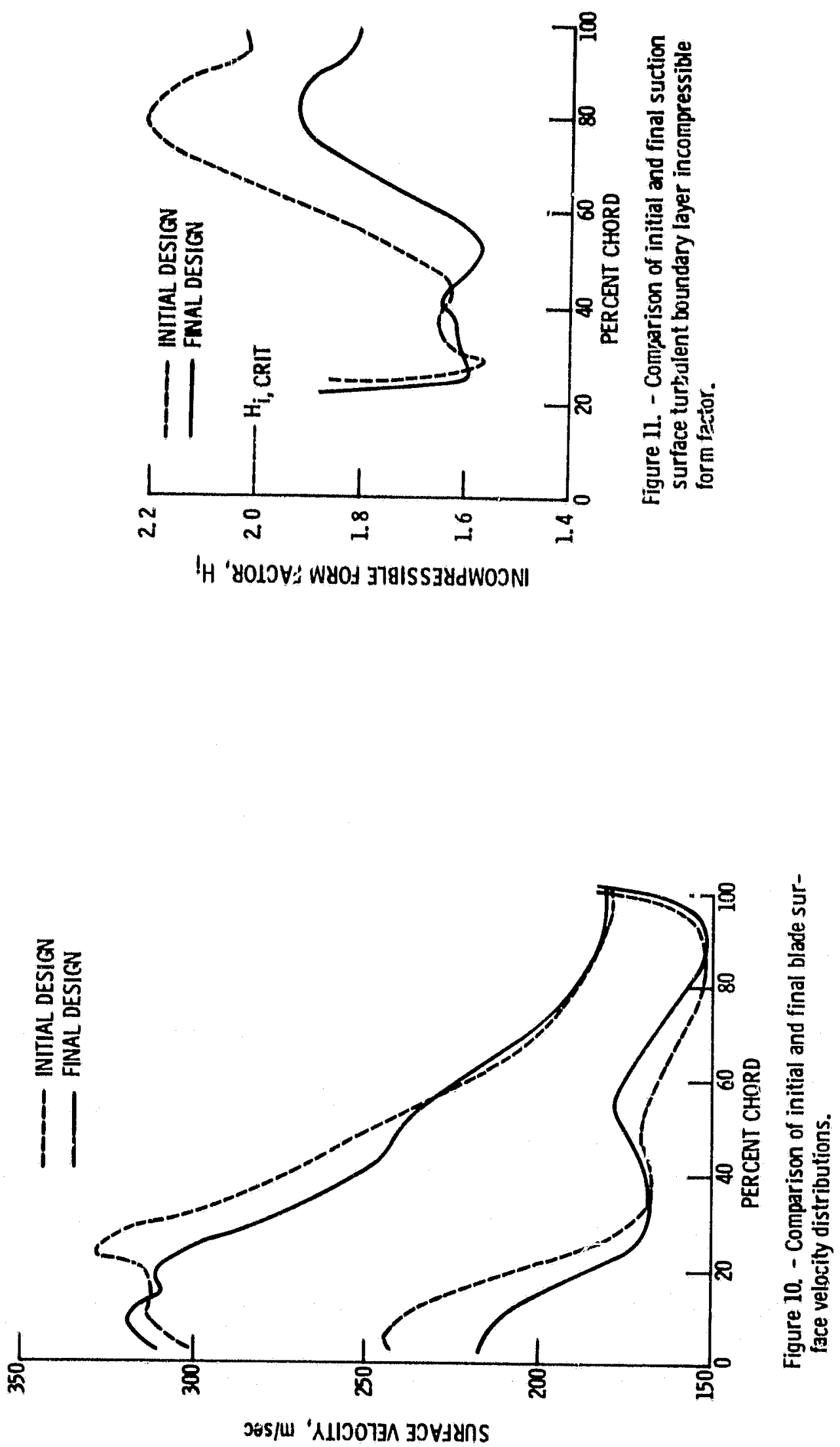

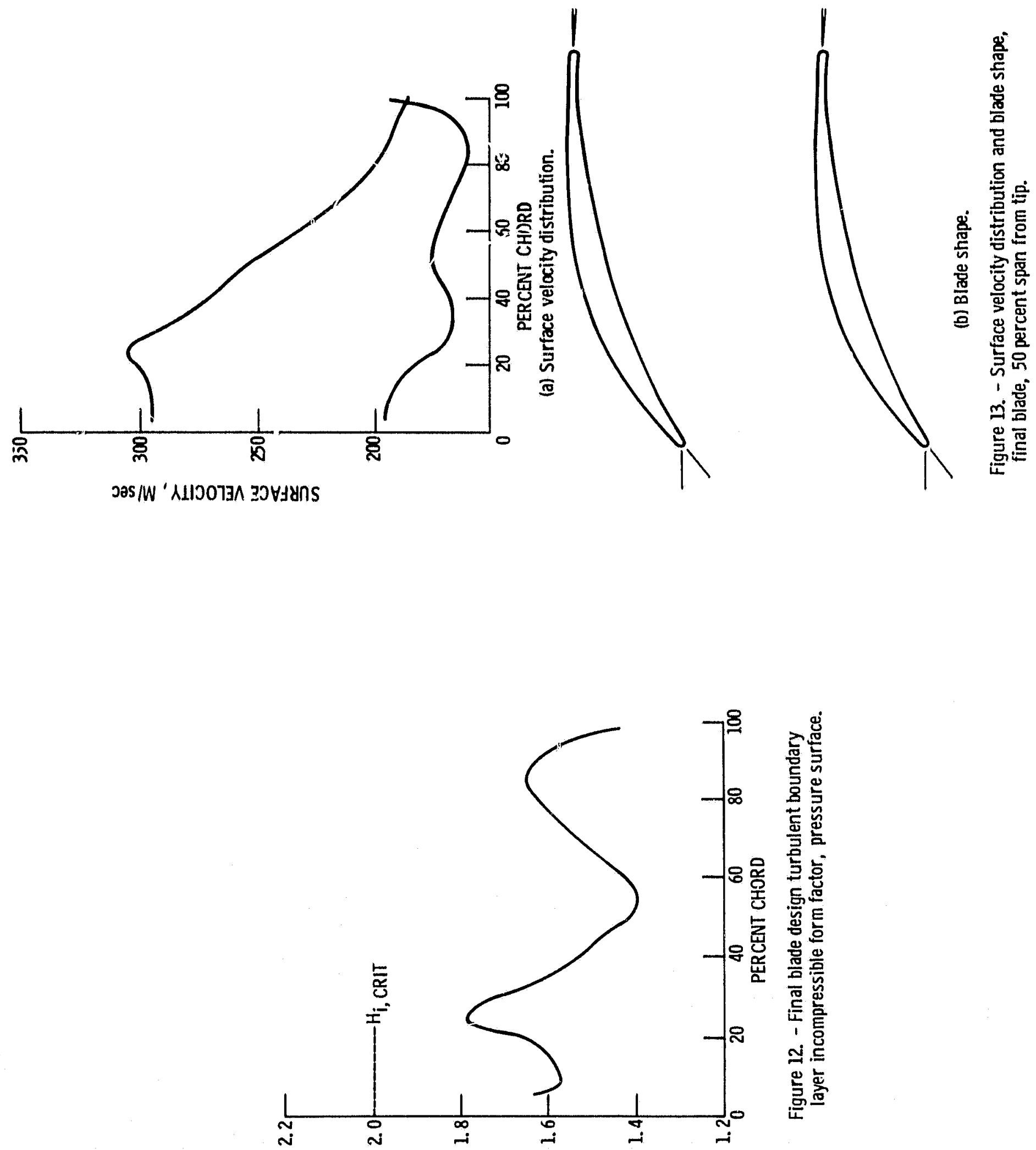

IH ' 


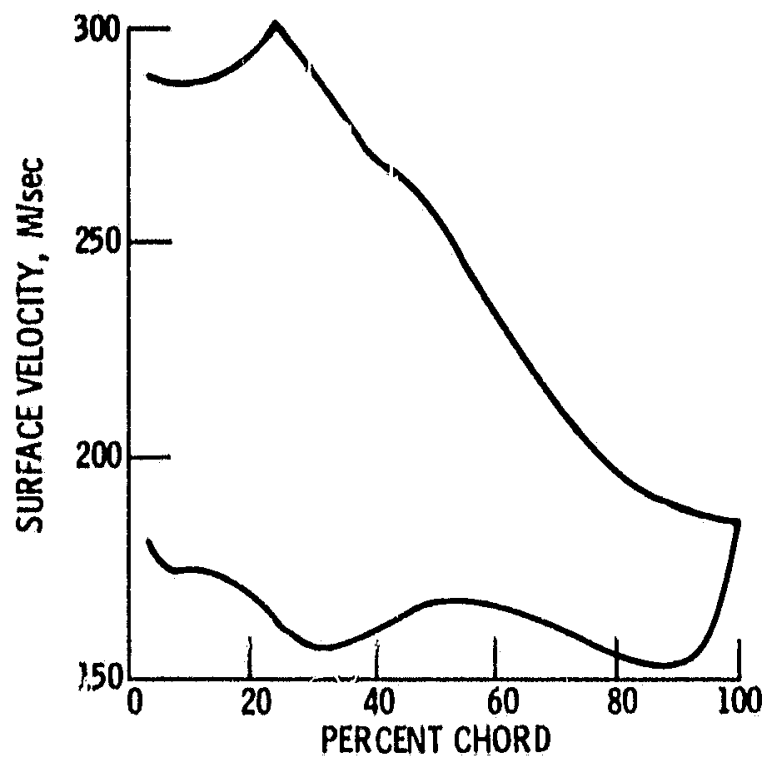

(a) Surface velocity distribution.
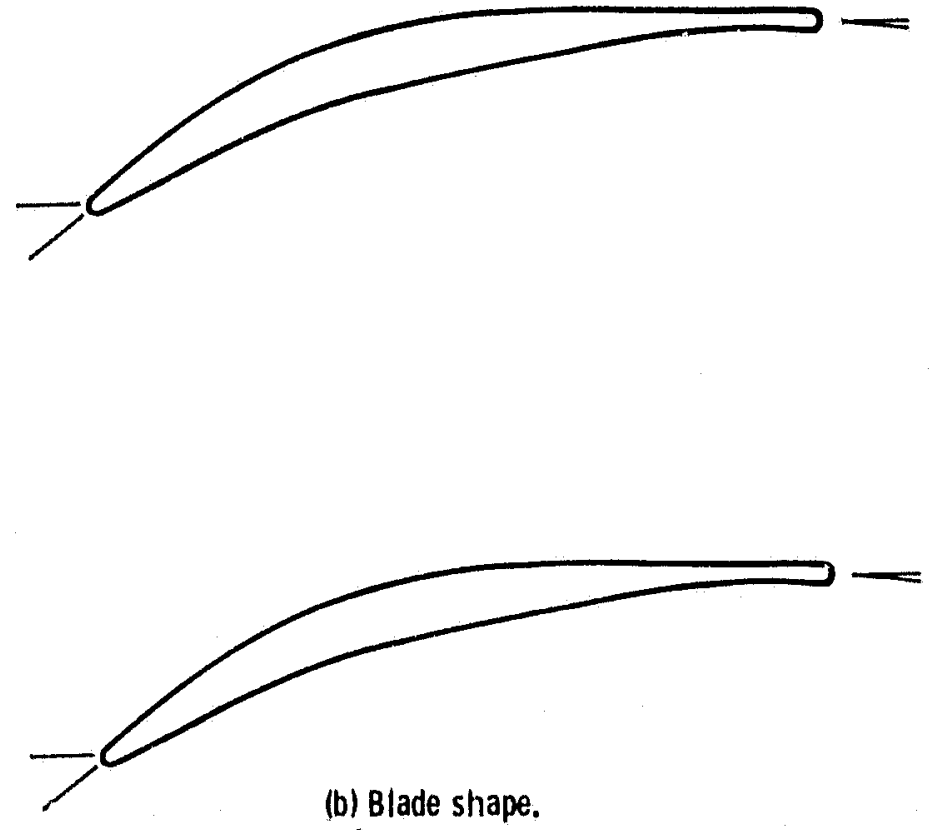

Figure 14. - Surface velocity distribution and blade shape, final blade, 10 percent span from tip. 